\section{Successful treatment of severe anemia using erythropoietin in a Jehovah Witness with non-Hodgkin lymphoma}

\author{
Alexandra Agapidou, Sofia Vakalopoulou, \\ Theodosia Papadopoulou, \\ Christina Chadjiaggelidou, \\ Vasileia Garypidou \\ Department of Hematology, Second \\ Propaedeutic Internal Medicine, Aristotle \\ University of Thessaloniki, Greece
}

\section{Abstract}

Blood transfusion many times works in a life-saving way when a patient is facing a critical situation. However, some patients, such as Jehovah's Witnesses, may refuse their administration because it opposes to their religion beliefs. Thus, clinicians are forced to respect patients' preferences and seek other treatments in order to overcome the obstacle of the transfusion. In 1989, recombinant human erythropoietin (rHuEPO) was approved by the United States Food and Drug Administration (FDA) for the treatment of anemia associated with chronic renal failure. This is an amino acid glycol-protein that stimulates red blood cell production in the same manner as endogenous erythropoietin. Other treatment indications approved by the FDA include anemia due to chronic kidney disease, anemia secondary to zidovudine therapy in patients with human immunodeficiency virus infection, and anemia secondary to cancer chemotherapy. The drug also has been used for many off-label indications. Many Jehovah's Witnesses have accepted rHuEPO as a treatment option to maintain and enhance erythropoiesis. This paper reports the case of a 57-year-old Jehovah's Witness man, who was diagnosed with severe anemia due to aggressive non Hodgkin lymphoma and refused transfusion of blood; thanks to the treatment with rHuEPO he has managed to complete chemotherapy and has survived a life threatening situation.

\section{Introduction}

Critically ill patients often need blood transfusion or any other blood product when they are facing a life threatening situation. However, some patients, such as Jehovah's Witnesses (JW), may refuse their administration due to religious beliefs. Based on those believes, humans must not sustain life with other creatures blood, (Genesis 9:3-4, Leviticus 17:10-11). If these directives are not followed, members face the risk of being ostracized or excommunicated. ${ }^{1}$ So physicians have to solve the difficult problem of treating patients, who are JW without offending their religious beliefs. It is clear that refusal of blood transfusion is associated with increased morbidity and mortality and health care system is charged with higher expenses. Studies have showed that a nadir hemoglobin $(\mathrm{Hb})$ concentration is a poor predictor of mortality of JW patients with anemia due to early (age $\geq 45$ years old, weight $\geq 90 \mathrm{~kg}$, hypertension, cardiac arrhythmia, angina, previous myocardial infarction, valvular heart disease, heart failure, being on hemodialysis, acute admission and $\mathrm{Hb} \leq 80 \mathrm{~g} / \mathrm{L}$ on admission to hospital) and late (shock, acute gastro-intestinal bleeding, pneumonia, nadir $\mathrm{Hb}$ concentration $\leq 70$ $\mathrm{g} / \mathrm{L}$, septicemia, worsened congestive heart failure and neurologic complications) mortality risk factors. ${ }^{2}$ Since recombinant human erythropoietin (rHuEPO) became available, several cases have been reported in which rHuEPO was successfully administered to critically ill JW. Administration of rHuEPO in combination with other blood conservation techniques has been shown to increase hemoglobin levels and survival in patients who experienced trauma, surgery, gastrointestinal bleeding or potential fatal hematological malignancies like lymphoma. However, there are not sufficient recommendations concerning transfusion in critically ill patients. Even though JW patients do not accept blood transfusion, it is possible to overlap this obstacle especially in critically ill patients by giving alternative and effective treatment like recombinant human erythropoietin.

This case report describes the successful treatment of a JW severe anemia, due to newly diagnosed non-Hodgkin lymphoma - grade IV, with recombinant human erythropoietin.

\section{Case Report}

A 57-year-old patient was admitted to our clinic due to high fever and lymphadenopathy. He complained for fever, up to $39^{\circ} \mathrm{C}$, for five days despite the fact he received intravenous antibiotic treatment, piperacillin-tazobactam (i.v.) and doxycycline (per os), for 5 days in a peripheral hospital. From his past medical record, he had known HBV hepatitis treated with tenofovir disoproxil for four months. From his clinical examination during his admission, he had hepatosplenomegaly, and palpable tracheal, axillary, inguinal lymph nodes on both sides. The computed tomography (CT) scan confirmed the generalized lymphadenopathy with no other signs of infection. The examina-
Correspondence: Alexandra Agapidou, Department of Hematology, Second Propaedeutic Internal Medicine, Aristotle University of Thessaloniki, University Campus, 54124 Thessaloniki, Greece. Tel.: +30.2310.996.000.

E-mail: alekagapidou@yahoo.gr

Key words: erythropoietin, rHuEPO, Jehovah's Witness, lymphoma

Contributions: the authors contributed equally.

Conflict of interests: the authors declare no potential conflict of interests.

Received for publication: 16 August 2014.

Revision received: 17 September 2014.

Accepted for publication: 3 October 2014.

This work is licensed under a Creative Commons Attribution NonCommercial 3.0 License (CC BYNC 3.0).

(C) Copyright A. Agapidou et al., 2014

Licensee PAGEPress, Italy

Hematology Reports 2014; 6:5600

doi:10.4081/hr.2014.5600

tions for any bacterial or viral infection was negative except for the HBV infection (HBsAg, Anti-HBe, Anti-HBc: positive). Recurring blood and urine cultures were negative. The antibiotic treatment with ciprofloxacin which started during admission was discontinued after 10 days, as there was no evidence of infection. Laboratory data disclosed pancytopenia with severe anemia (Ht: $20.5 \%, \mathrm{Ht}: 7.4 \mathrm{gr} / \mathrm{dL}$ ) neutropenia (WBC: $1.6 \times 10^{3} \mu \mathrm{L}$, neutrophils: $36 \%$, lymphocytes: $52 \%$ ) and thrombocytopenia (platelets: $74 \times 10^{9} / \mathrm{L}$ ). The bone marrow aspiration and bone marrow biopsy had no signs of infiltration from any kind of malignancy while the lymph node biopsy revealed histological picture compatible with non-Hodgkin lymphoma diffuse large B cell lymphoma type, high grade, (CD 20, CD79: positive, CD3, CD5, CD10, CD23, Cyclin D1: negative).

Investigation concerning the cause of his anemia was done, including measurement of vitamin B12 and folic acid which were among normal levels but ferritin was increased ( 2286 $\mathrm{g} / \mathrm{dL}$ ) probably acting as acute phase protein. Fever was considered more as a B-symptom due to its pattern of appearance (mainly afternoon time) and his diagnosed underlying lymphoma. Patient had 4\% Auckland anemia mortality risk score (AMRS) and 4\% Hamilton AMRS. ${ }^{3,4}$ The patient was informed about the seriousness of his condition and that he should start chemotherapy and blood transfusions. Although recent data suggest that critically ill patients in general can tolerate anemia to an $\mathrm{Hb}$ level of $7 \mathrm{~g} / \mathrm{dL}$, concerns have been raised that this level of anemia may not be well tolerated by certain critically ill patients as the 
patient herein who had to undergo chemotherapy for an aggressive hematologic malignancy. He didn't oppose to the chemotherapy but he strongly refused, in a written form, blood transfusion as this was against his believes. The health care professionals were obliged to respect patient's preferences, and seek alternatives to blood transfusion. He was proposed to use rHuEPO and he agreed to that kind of treatment. The patient was monitored primarily by hematologists but he had consultations with gastroenterologists as well, due to his HBV infection without having any kind of intervention beside his HBV treatment. There were no patient-doctor relationship issues of any kind. He started darbepoetin alfa $300 \mathrm{mg}$ once every week immediately ( $\mathrm{Hb}: 7.5 \mathrm{~g} / \mathrm{dL}$ ). He also started chemotherapy (R-CHOP) after one week from his admission. His temperature went back to normal. He continued chemotherapy without any side effects and on the third cycle of R-CHOP, hemoglobin levels was 11.5 $\mathrm{g} / \mathrm{dL}$. He finished 6 cycles of R-CHOP after six months without receiving blood transfusion and with hemoglobin levels being $13.5 \mathrm{~g} / \mathrm{dL}$ at his final chemotherapy cycle.

\section{Discussion}

This clinical case highlights some of the therapeutic challenges that can be met in the treatment of severe anemia in a patient who does not wish to receive blood transfusion. ${ }^{1}$ Evaluation of religious beliefs that affect treatment, such as transfusion preferences, should be made initially, and the patient and/or family provided with information and thereby the ability to make an informed choice. When a patient refuses a treatment option and could die in a potentially treatable situation creates an ethical dilemma for the health care professional, as well as being a frustrating experience. ${ }^{5,2}$ Whole blood as well as its components, erythrocytes, white blood cells, platelets and plasma are considered prohibited. However, there is some variation within the religious group, with some members accepting components such as albumin, recombinant human erythropoietin and immunoglobulin. This must be discussed with each individual patient in order to apply his/her personal choice. ${ }^{1}$

Without the possibility of transfusion as the standard treatment of severe acute anemia, clinicians must use supportive techniques to improve the patient's own circulation and oxygen-carrying capacity. ${ }^{1} \mathrm{EPO}$ is an endogenous hormone produced primarily by the kidneys that stimulates the bone marrow to produce red blood cells in response to hypoxemia. Using recombinant DNA technology, exogenous EPO is now commercially available and is routinely used to treat anemia in pre-dialysis patients, patients with end-stage renal failure, and patients infected with HIV with anemia related to zidovudine therapy. In JW patients, EPO has been proposed as an alternative to administering blood products to replace lost blood or to increase their vascular volume before elective surgery. ${ }^{6-9} \mathrm{EPO}$ has been useful in the JW reported in the literature in whom it has been used instead of blood or blood products. ${ }^{10,11}$ The Watchtower Society's Bible Information Services has stated that the use of EPO should not be objectionable in JW who receive treatment with EPO because this synthetic hormone is a product of recent technology. There might, however, be some individual JW who would find it unacceptable to use a solution that contains albumin. Each individual must decide if it is appropriate.

\section{Conclusions}

Refusing blood transfusions may have complications. The case reported here shows that it is possible to survive with hemoglobin lower than $7.5 \mathrm{~g} / \mathrm{dL}$ and receiving in the meantime chemotherapy for an aggressive hematological malignancy. Early initiation of rHuEPO therapy may be required to achieve optimal response in Jehovah's Witnesses, who are a group of patients with different attitude towards blood transfusion and must be treated with respect to their beliefs.

\section{References}

1. Lorentzen K, Kjær B, Jørgensen J. Supportive treatment of severe anaemia in a Jehovah's Witness with severe trauma. Blood Transfus 2013;11:452-3.

2. Beliaev AM. High-risk anaemic Jehovah's Witness patients should be managed in the intensive care unit. Blood Transfus 2013;11:330-2.

3. Beliaev AM1, Marshall RJ, Smith W, Windsor JA. Treatment monitoring and mortality risk adjustment in anaemic Jehovah's Witnesses. ANZ J 2013;83:161-4.

4. Beliaev AM1, Marshall RJ, Smith W, Windsor JA. Mortality risk stratification in severely anemic Jehovah's Witness patients. Intern Med J 2012;42:e1-3.

5. Berend K, Levi M. Management of adult Jehovah's Witness patients with acute bleeding. Am J Med 2009;122:1071-6.

6. Pousada L, Fiorito J, Smyth C. Erythropoietin and anemia of gastrointestinal bleeding in a Jehovah's Witness. Ann Intern Med 1990;112:552.

7. Brooks BJ, Hanson DS, Cryer PA, et al. Erythropoietin therapy for sickle cell anemia in Jehovah's Witnesses. South Med J 1991;84:1416-7.

8. Green D, Handley E. Erythropoietin for anemia in Jehovah's Witnesses. Ann Intern Med 1990;113:720-1.

9. Kyger ER, Blakestad BR. Synthetic erythropoietin and Jehovah's Witnesses. J Thorac Cardiovasc Surg 1991;101:369.

10. de Araújo Azi LM, Lopes FM, Garcia LV. Postoperative management of severe acute anemia in a Jehovah's Witness. Transfusion 2014;54:1153-7.

11. Ukachi N, Morrison W, Vanhorn S, et al. A young adult Jehovah's Witness with severe anemia. Pediatrics 2013;132:547-51. 